\title{
A Research on Dynamic Relationship between OFDI and Industrial Structure Optimization-A Case Study of Guangdong Province
}

\author{
Ziqi Ye \\ School of Economics, Jinan University, Guangzhou, China \\ Email: yeziqi0504@foxmail.com \\ Received 16 December 2015; accepted 22 January 2016; published 25 January 2016 \\ Copyright (C) 2016 by author and Scientific Research Publishing Inc. \\ This work is licensed under the Creative Commons Attribution International License (CC BY). \\ http://creativecommons.org/licenses/by/4.0/

(c) (i) Open Access

\begin{abstract}
Regarding the data from 2003 to 2013 of the typical opening city in Guangdong province, this paper is going to use the VAR model to study the dynamic relationship between OFDI and industry optimization. And we come to the conclusion that the industry structure rationalization exerts a more significant auxo-action on OFDI than the latter does on the former; however, there is no significant Granger relationship between OFDI and industry structure advancement. According to above results, this paper tries to give an economic explanation combining with current situation of OFDI.
\end{abstract}

\section{Keywords}

Industrial Structure Optimization, Outward Foreign Direct Investment (OFDI), VAR Model

\section{Introduction}

The trend of economic globalization is irreversible, and China's economic growth is closely connected with the opening to the outside world. Since the inception of China's reform and opening-up policy, especially China's accession to the WTO (World Trade Organization), China's outward economy rapidly develops; especially China's outward foreign direct investment (OFDI) sees a qualitative leap. In 2014, China's OFDI flow was 123.12 billion dollars, 45.6 times of that in 2002, and the stock was 882.64 billion dollars, which allowed China to be ranked world top 10 for the first time. Under new situations, the "go-out" strategy is a major open policy strategy China adopts in the ever-changing global political and economic pattern, and quintessence of the "one- 
belt and one-road" strategy is the orderly and free flow of economic factors, the efficient resource allocation and in-depth market integration propelled by the "go-out” strategy to realize China's economic upgrading and rebalance. The participation in the international division of labor and transfer of surplus productivity through OFDI of capital, technologies, management experience and other factors can effectively promote China’s economic and industrial structure adjustment and upgrading, and how does the industrial structure optimization and upgrading influence OFDI? To explore the relationship between OFDI and industrial structure optimization is of important theoretical and practical significance to drive the economic transformation and upgrading and the sustainable and healthy development of OFDI, and to push the establishment of long-term and stable commercial trading network relationships with the world.

Guangdong Province, by virtue of the advantages of its natural geometrical location of neighboring sea and bordering on Hong Kong and Macao, and the national policies, always takes stable lead in the whole country regarding the import-and-export trades, attraction of foreign investment and OFDI development. From 1998 to 2014, the total export-import volumes of Guangdong Province was ranked top 1 for consecutive 27 years; from 2003 to 2013, Guangdong Province kept continuous and stable growth in the non-financial OFDI, and leaped to and remained No. 1 nationwide. With the starting of “one-belt and one-road” project, more and more enterprises coming from different cities will "go out"; besides the common features that other cities in China do, Guangdong Province has kind of guiding and typicality in its economic development practices, so the paper conducts discussion and analysis with Guangdong Province as the case.

\section{Literature Review}

The foreign countries started early in the research on the relationship between OFDI and the domestic industrial structures, and the early researches were dominated by theories. The early research objects were the developed countries, and the representatives are the "Product Life Cycle Theory" proposed by Raymond Vernon [1], the “Theory of Labor Intensive Industry Transfer” proposed by W. A. Lewis [2], the "Marginal Industry Expansion Theory” proposed by K. Kojima [3], etc. With the continuous deepening of the international division of labor, many developing countries also commenced OFDI. A new round of related research results emerged, such as, T. Ozawa’s [4] “Integrative International Investment Development Theory”, J.H. Dunning’s Strategic Asset Motive Acquisition Investment Theory [5], etc. With the gradually mature development of OFDI practices and theories, different methods and tools are applied to conduct the empirical study on the influence on industrial structure adjustment from OFDI; the conclusion that OFDI did promote the industrial structure adjustment of the investment countries has been unanimously identified by the industry scholars, and the typical ones are Dowling [6], Robert [7], etc.

China has a late start in the research on the relationship between OFDI and the industrial structures of the investment countries as well as the related functional mechanisms; but with the constant development of China's OFDI practices, the related theories and research methods are gradually matured and improved. Wang Qi [8] thought that OFDI had obviously positive and negative effects on the industrial structure adjustment of the investment countries, and OFDI influenced the speeds and efficiency of industrial upgrading of the investment countries through influencing the investment factors, demand structures and resource transformation methods of the investment countries. Fan Huanhuan and Wang Xiangning [9] used the Auto-regression Distributed Lag Model (ADLM) to analyze the influence on China's industrial structures from OFDI, and made a comparative study of the OFDI scales and industrial structures of USA, Japan and Korea. Feng Chunxiao [10] conducted the empirical analysis to discover that OFDI for the manufacturing industry had a positive influence on its industrial structure optimization through establishing and measuring the indicators of the structural rationalization and upgrading of the manufacturing industry. Zhao Wei and Jiang Dong [11] summarized that ODI generally had three operational channels of industrial transfer, industrial association and intra-industry competition for the mother countries' industrial upgrading, and reached that ODI did have some positive influences on the industrial upgrading in the typical areas by empirical researches. Zhao Ming and Zhang Rong [12] established the VAR model to analyze the correlation between OFDI and industrial structures of Jiangsu Province and summarized that OFDI and industrial structures of Jiangsu Province maintained a long-run equilibrium relationship.

To sum up, the researches on the relationship between industrial structures an OFDI and mechanisms mainly have the following two features: the first one is that the early researches are mainly dominated by theory studies and few start from the provincial level, The second one is the research objects, research methods and research angles gradually became diversified in the middle-late stages, but most of the researches elaborated the one- 
sided influence on industrial structures from OFDI and few made the empirical exploration about the influences on OFDI from industrial structures. Therefore, in the new period of economic restructuring, the paper shall select Guangdong Province, the typical region of OFDI in China, for the empirical researches and further discuss the influence paths on OFDI from industrial structures.

\section{Variable and Model Selection}

The paper focuses on exploring whether industrial structures influence OFDI or not and the corresponding influence paths, but to analyze the interaction relations among variables more accurately, we will firstly make an empirical exploration of the mutual effects between the two variables of industrial structure levels and OFDI. The variables involved in the path exploration shall be confirmed by the correlation among the relevant economic variables in the priori theory, and structuring method for the same kind of indicators keeps consistent in the whole text, and below we will firstly introduce the structuring methods and data sources of industrial structure levels and OFDI.

\subsection{Variable Selection}

Measure indicator of industrial structure level GSR: The foreign countries measure the industrial structure level from the national level, and there are generally two measurement methods. The first method is the comparison method by establishing the "standard" structure. The "standard" structure is obtained through regression analysis for the main factors which influence the sample countries and reflect the industrial structures by establishing the model and applying the statistical analysis method based on collecting the specific data of industrial structure evolution for many countries. And the second one is the discrimination method of relative comparison, that is, whilst discriminating an industrial structure level, use another industrial structure as the reference system for evaluation and discrimination. The domestic scholars also obtained some achievements in their researches on the industrial structure level measurement, and the two outstanding indicators are the industrial structural rationality and industrial structural upgrading, but there are many specific structuring methods for the two indicators and no authoritative opinion has been formed so far.

The industrial structural rationality measures the coordinated development degree among industries, and can be reflected by the coupling degree between the input factor structure and industrial structure. The deviational range of industrial structure (GSR) is often used to measure the rationalization level, as shown in Equation (1), $Y$ represents the gross regional domestic product, $L$ represents the number of regional employees, and represents the $i^{\text {th }}$ industry. After the equality transformation (the equality after the second equal mark), the coordinated development relations among industries are reflected from the perspective of productivity, but the perspective attaches the same weights to the three industries, but neglects the contribution degrees of different industries for the economic development. Given this, the paper shall adopted the indicator structuring method used by Jin Tao and Chen Jiajia [13], as shown in Equation (2), it not only reserves the measurement mechanism of the deviational range of industrial structures, but also adds the relative importance of different industries, which represents the significance of industrial structure rationality in a more comprehensive manner. The smaller the GSR value is, the more rational the industrial structure is and the more balanced the economic structure tends to be. Industrial advancement is used to delievert the degree of optimization of intra-industry, reflects a trend of highprocessing, highly value-added, knowledge-intensive and skill-intensive in the intra-industry. Hoffman coefficient (HOF) represents the ratio of the net output of consumption industrial and the net output of capitalist industrial, which is commonly used to measure the level of industrial advancement, the higher degree, the smaller the ratio is. Because there is no corresponding statistical data in China, this paper will use the ratio of light industry and heavy industry sales value instead.

$$
\begin{gathered}
E=\sum_{i=1}^{n}\left|\frac{Y_{i} / Y}{L_{i} / L}-1\right|=\sum_{i=1}^{n}\left|\frac{Y_{i} / L_{i}}{Y / L}-1\right| \\
G S R=\sum_{i=1}^{n} \frac{Y_{i}}{Y}\left|\frac{Y_{i} / L_{i}}{Y / L}-1\right|
\end{gathered}
$$

Measure indicator of OFDI: As for the other variable OFDI which will be emphatically studied in the paper, the proportion of non-financial OFDI amount and gross regional domestic product shall be the OFDI indicator to 
participate in the model construction. Using the proportion indicator, on one hand, removes the influence of inflation rate, and on the other hand, keeps consistent with the indicator structuring of industrial structures in dimension.

\subsection{Data Sources}

The data of the gross domestic product of Guandong Province and the original data of employees at the end of the year in Guangdong Province used for the structuring of Variable 1 indicator are from the Statistical Yearbook of Guangdong Province and the Yearbook of Chinese Industry. And the OFDI data used for the structuring of Variable 2 indicator come from the Statistical Bulletin of China's Outward Foreign Direct Investment issued by Ministry of Commerce. Since the provincial OFDI data started its earliest publish in 2003, the paper selects the time-series data from 2003 to 2013 for VAR modeling and analysis.

\subsection{Construction of VAR Model}

The vector auto-regression model (VAR) is not based on the economic theories, but adopts the form of multi-equation simultaneous, use the endogenous variable to regress the lag phase of all the endogenous variables, and explores the dynamic relations among all the endogenous variables. At present, VAR Model is commonly used to predict the correlative system of economical time series, analyze the dynamic impact on the variable system from the stochastic disturbance, and explain the long-run relations among the related economic variables. And the expression of the VAR Model with the lag order is:

$$
Y_{t}=A_{1} Y_{t-1}+A_{2} Y_{t-2}+\cdots+A_{p} Y_{t-p}+B X_{t}+\mu_{t} \quad(t=1,2, \cdots, n)
$$

where, $Y_{t}$ is the endogenous variable vector outside dimension, $X_{t}$ is the endogenous variable vector inside dimension, $u_{t}$ is the error vector of dimension, $A_{1}, A_{2}, \cdots, A_{p}, B$ is the estimated coefficient matrix. The paper intend to explore the long-run dynamic influence between industrial structure upgrading and OFDI, that is, GSR and LNOFDI shall be used as the endogenous variables and constant variables is defaulted as exogenous variables. Due to the number of year of the data can't meet the multivariate analysis of the VAR model building, the rationalization of industrial structure and advancement of industrial structure indexes will build VAR model with OFDI index respectively, the VAR model built by GSR and OFDI will be called as model 1, model 2 is the other one, and the model will be built by evaluating the logarithm of above three indexes.

\section{Empirical Test and Result Analysis}

\subsection{ADF Test}

While studying whether the economic variables have long-run relations or not, we firstly need to test the stability of the time series. Strictly speaking, in a VAR model with the variable m, all the m variables shall be (jointly) stable, otherwise, it is necessary to properly change data. The paper adopts ADF test method to test the stability of variables. Shown in Table 1, ADF statistics are smaller than the critical values, the indicator LNOFDI, LNGSR and LNHOF are all in stability in the original series, so they can be used for the establishment of a long-run model.

\subsection{The Confirmation of the Optimal Model Lag Phase}

The selection of the lag phases of the explanatory variable within the system is the key to the VAR model, and

Table 1. ADF test results.

\begin{tabular}{ccccc}
\hline Variables & Test forms & ADF statistical test quantity & Critical value & Conclusion \\
\hline LNOFDI & $(0,0,0)$ & -1.982344 & $-2.238120^{* * *}$ & Stable \\
LNGSR & $(\mathrm{C}, \mathrm{T}, 0)$ & -5.017989 & $-4.107833^{* *}$ & Stable \\
LNHOF & $(\mathrm{C}, 0,0)$ & -3.550819 & $-3.259808^{* *}$ & Stable \\
\hline
\end{tabular}

Note: ${ }^{* *}$ and ${ }^{* * *}$ respectively indicate the result is significant under the level of $5 \%$ and the level of $1 \%$; $\mathrm{C}$, $\mathrm{K}$ and $\mathrm{T}$ respectively indicate the roots of unity, including constant terms, time trends and lag orders. 
selecting irrelevant lag phases probably cause adverse effects on the analyzing results. As a general rule, if the lag phase is too small, the self-correlation of the error terms is serious and it also causes the non-consistency estimates of the parameters; otherwise, it causes the decrease of degree of freedom and influences the effectiveness of the model parameter estimates. The paper selects the lag orders based on the 5 commonly used indicators of eviews 6.0: LR, FPE, AIC, SC and HQ. The results in Table 2 show that model 1 statistics indicator criterion all select 2 lag phase. The indicators above excluding the fomer two in the model 2 all select 2 as the optimal value of $\mathrm{K}$, therefore, it can be inferred the VAR (2) model is the optimal model to both.

\subsection{Stability Test}

It is also very important to test the stability of the model; if the estimated model is unstable, some results obtained are invalid. If the reciprocals of the roots of the characteristic equation of the VAR model are less than 1 (within the unit circle), the model is stable; if any are outside the unit circle, the model is unstable. Shown in Figure 1, the left one is the distribution diagram of reciprocals of the roots of the characteristic equation of the VAR model 1, the right one is of model 2. The VAR (2) model is completely stable, therefore, we can go further study.

\subsection{Granger Causality Test}

Granger Causality is used to check whether all the lag terms of a variable influence the current values of the other one or several variables. If the influence is significant, it means that Granger Causality exists between the variable and the other one or several variables; otherwise, Granger Causality doesn't exist. The null hypothesis of causality test is that the tested variable is not the causality of the dependent variable, if the test probability $\mathrm{P}$ value is less than the given confidence level (generally 5\%), then the tested variable is the causality of the dependent variable; otherwise, the tested variable is not the causality of the dependent variable. The test results in

Table 2. The confirmation of the optimal lag phases in VAR model for GSR and LNODI.

\begin{tabular}{ccccccc}
\hline Model & Lag phases & LR & PFE & AIC & SC & HQ \\
\hline \multirow{2}{*}{1} & 0 & NA & 0.002169 & -0.4596 & -0.41577 & -0.55418 \\
& 1 & 16.7142 & 0.000343 & -2.35641 & -2.22493 & -2.64015 \\
& 2 & $9.719611^{*}$ & $9.24 \mathrm{e}-05^{*}$ & $-3.897425^{*}$ & $-3.678286^{*}$ & $-4.370325^{*}$ \\
\hline \multirow{2}{*}{2} & 0 & $\mathrm{NA}^{*}$ & 0.000178 & -2.96079 & -2.91697 & -3.05537 \\
& 1 & 9.123913 & $9.95 \mathrm{e}-05^{*}$ & -3.59256 & -3.46107 & -3.8763 \\
& 2 & 3.951988 & 0.000113 & $-3.691663^{*}$ & $-3.472525^{*}$ & $-4.164563^{*}$ \\
\hline
\end{tabular}

Note: ${ }^{*}$ Bases on the relevant criterion to select the optimal lag phase.

Inverse Roots of AR Characteristic Polynomial

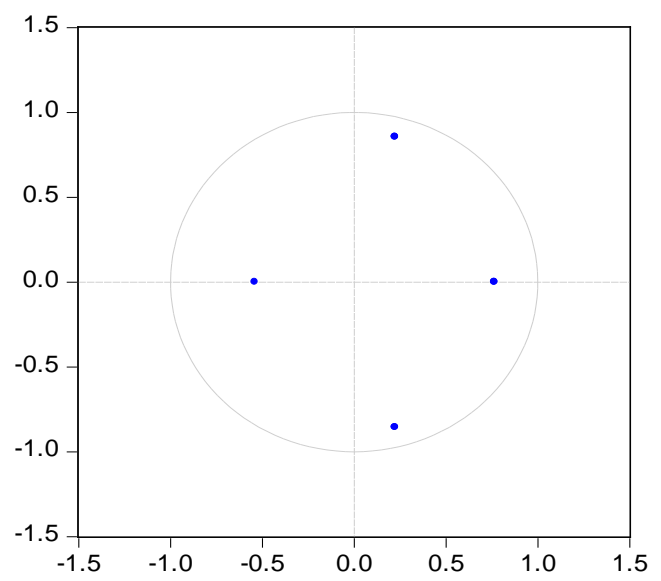

Inverse Roots of AR Characteristic Polynomial

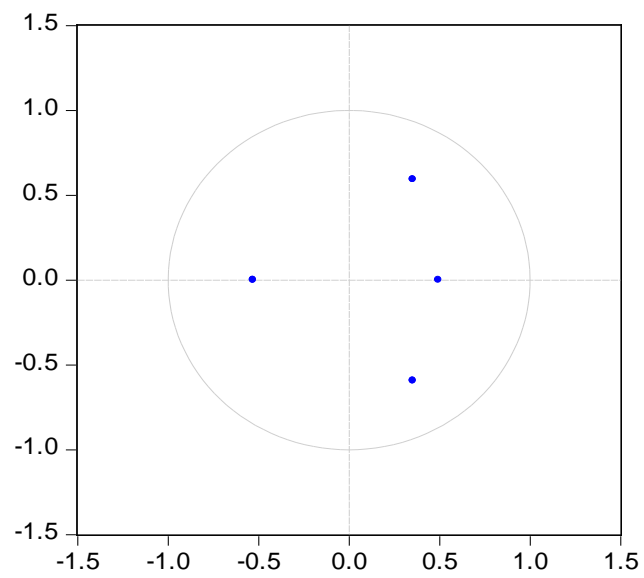

Figure 1. The distribution diagram of reciprocals of the roots of the characteristic equation of the VAR model. 
Table 3 show that the lagged variables of LNOFDI are not the Granger causality of GSR statistically, and GSR is the significant Granger causality of LNOFDI statistically in model 1, LNHOF and LNOFDI is neither the other's Granger causality in model 2.

\subsection{Impulse Response}

The impulse response function is used to describe the response of an endogenous variable to the impacts from error terms, that is, the influence amplitude and duration caused to the current and future values of the endogenous variable by the impact from a variable. In the figure, the full line represents the impact response of a variable to other variables, and the imaginary lines at both sides represent the deviational zones caused by the positive and negative double standard errors. For LNHOF and LNOFDI is neither the other's Granger causality, they both has a weak statistical contact with each other, the following will implement the impulse response analysis on relationship between OFDI and structural rationality degree individually.

Figure 2 demonstrates the impulse response function formed by the positive impact in a standard error unit of the industrial structure rationality degree (LNGSR) to the OFDI changes (LNOFDI). In the first phase, LNGSR nearly has no reaction to LNOFDI, which means the current change of OFDI doesn't have immediate influences on the changes of the industrial structures. As time goes by, its influences gets greater, and reaches the peak in the third phase, and then weakens gradually and is near to 0 in the fifth phase, and appears a similar influence period with a small amplitude after the sixth phase. This states OFDI has a positive but lagged long-run influence on the industrial structure optimization, but judging from the deviational amplitude, the current effects are not significant.

Figure 3 demonstrates the impulse response of LNOFDI to LNGSR. After receiving a positive impact from the industrial structure rationality, LNOFDI immediately has a huge response in the current phase, and comes to the peak in the second phase, and then the influence weakens gradually and falls to the lowest point in the fifth phase, and appears a similar influence period with a smaller amplitude after the fifth phase. It is concluded that GSR tends to be smaller year by year by calculating the original data in the formula, so the original impact of LNOFDI from GSR is negative, and LNOFDI does the corresponding response behaviors.

Table 3. Granger causality test.

\begin{tabular}{clcccc}
\hline & Model null hypothesis & Lag phase & F statistics & Probability & Conclusion \\
\hline 1 & LNOFDI is not the Granger causality of GSR & 2 & 4.139493 & 0.1062 & Accepted \\
GSR is not the Granger causality of LNOFDI & 2 & 2 & 0.115503 & 0.9439 \\
2 & LNOFDI is not the Granger causality of LNHOF & 26614 & 2.156317 & 0.3402 \\
\hline
\end{tabular}

Response of LNGSR to LNOFDI

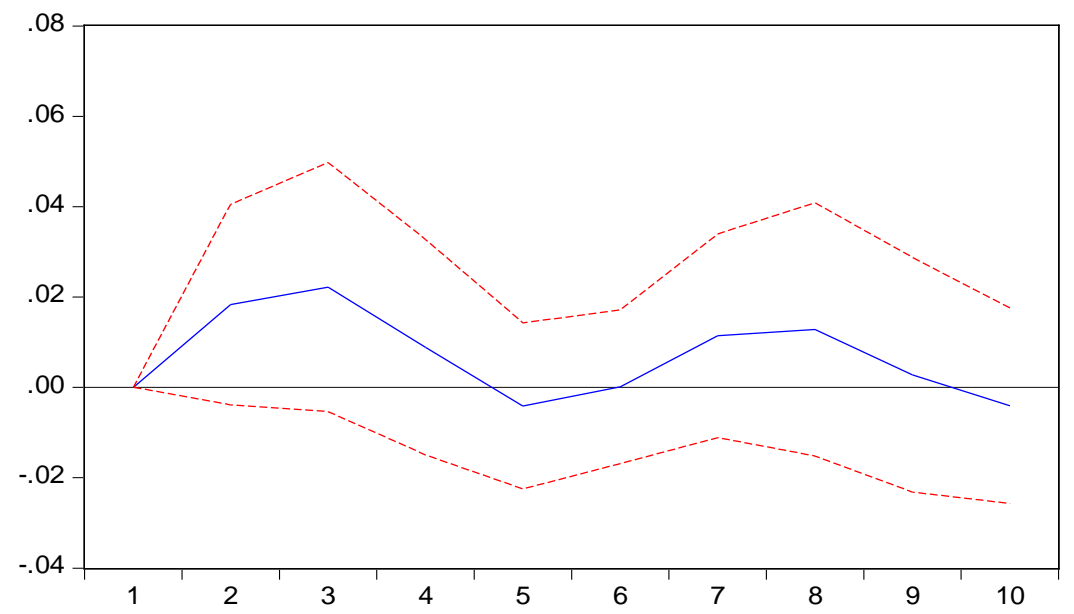

Figure 2. Impulse response of LNGSR to LNOFDI. 
Response of LNOFDI to LNGSR

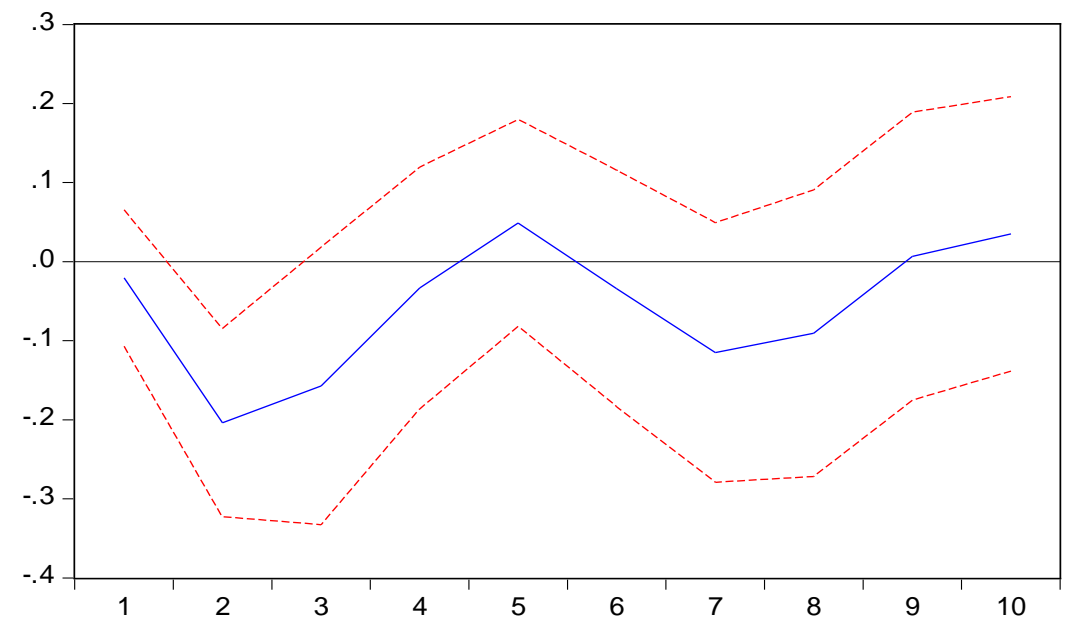

Figure 3. Impulse Response of LNOFDI to LNGSR.

\section{Economic Explanation}

To sum up, it can be obtained that OFDI and industrial structure rationalization of Guangdong Province have intimate and long-run interaction relationships at least statistically. Below we will make a preliminary explanation of the aforesaid results on it from the perspective of economic theories.

From the results of impulse responses, OFDI of Guangdong Province facilitates its industrial structure rationality but with small influence amplitude, and from the results of Granger causality test, we can know that OFDI of Guangdong Province doesn't form Granger causality to its industrial structure rationality obviously. Combining the indicator itself with the current development situation of OFDI, four reasons can be tried to explain it: the first one is that, the variable indicators and model structuring cannot comprehensively reflect the logical relationship between the economic information carried by the variables and variables; the second one is that, its OFDI has a short development history, small foreign investment scale, unclear aims and immature experience in investment practices, and all of these reasons make OFDI not to exert a very outstanding promotive effect on China's industrial and economic structures; the third one is that, the investors is mainly consist of kinds of science and technology companies whose type is comparatively single, and this results that OFDI can not obtain the power to make a great and comprehensive influence on whole industry until to now; and the last one is that, the target countries of investment mainly is developing countries which is close to China's level of development, so the positive spillover effect on metropolitan industry is still not easy to make a qualitative leap to some degree.

Above test results also indicate that, the changes of industrial structure rationality form Granger causality to OFDI, and have a long-run and large-amplitude influence on OFDI. From the information reflected by the industrial structure indicators structured by the paper, the possible direct reasons are as follows: the first one is, as the Figure 4 shows, the down trend of GSR reflects the industry structure of Guangdong Province is more and more rational, accompany this trend, labor, land, capital and other factors of production are got to be rational disposed, then the production efficiency also got promotion, which not only help to obtain the ability to "go out", but also drive the enterprise to go out to expand market share or to learn more advanced technologies; the second one is that, the indicators also reflect the balanced development trends of the three major industries, which also means that the number of enterprises who are capable of conducting foreign investment is growing, so the OFDI scale and speed are also in increase; the third one is, the rationalization of industry, at the same time, means the product manufacturing is more Standardized, high-tech, internationalized, which reduces the difficulty being synonymous with foreign production line of the enterprise, that help to accelerate the pace going outside to build factories, especially in some countries who has a comparative advantage in some resources what can be taken advantage of; the last one is that, with the improvement of production efficiency, product quality and the diversification of product, the demand coming from foreign continues to increase, considering the existence of tariffs and some other intermediate transaction costs, most firms choose to "go out". 


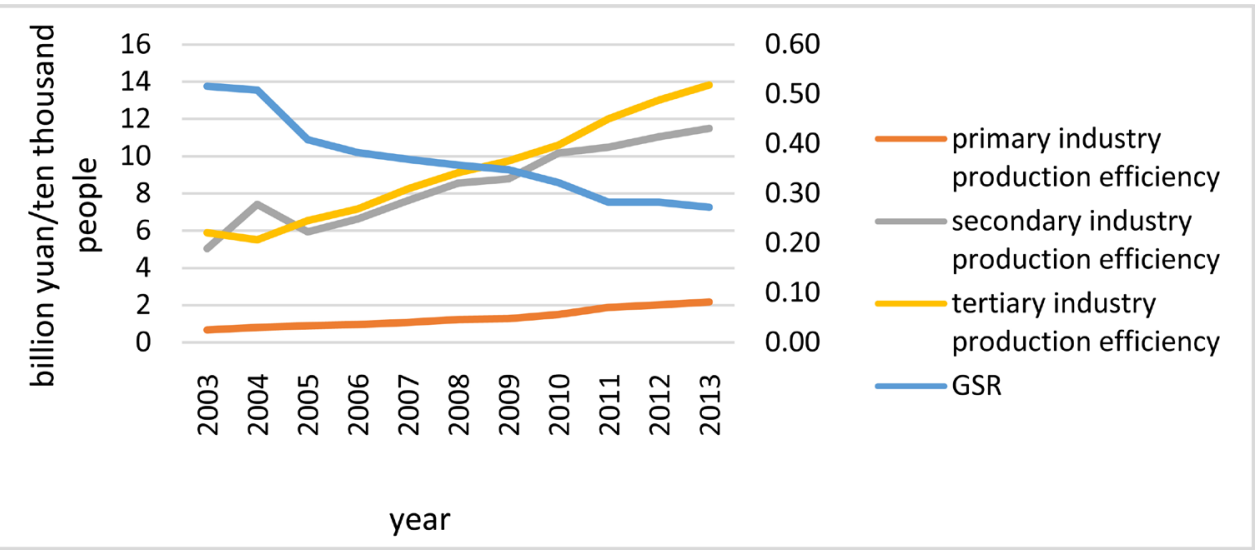

Figure 4. Three industries production efficiency in 2003-2013 and structural rationality of Guangdong province.

\section{Conclusions}

The test of industrial structure optimization and OFDI with VAR model shows that there is a long-dynamic positive relationship between them. On one hand, the granger causality test results show that the relation between OFDI and the rationalization of industrial structure is closer, and there is no obvious statistical causal relationship between OFDI and industrial structure supererogation, namely, by contrast, OFDI exerts much greater impact on inter-industry than intra-structure relationship. On the other hand, the probability $\mathrm{P}$ values of Granger Causality Test and results of impulse response analysis show that effects on industrial structure rationalization of OFDI and influence range still have large rising space. Therefore, we should grasp opportunities, with facing up to the problems faced by OFDI nowadays, and making the best of foreign direct investment effectively, to promote the development of industrial structure rationalization of home country. At the same time, the deepening of OFDI on how to improve the local industry development path remains to be exploited and guided.

Different from traditional mainstream research results, through the experiment of this paper we also can get this discovery: industrial structure rationalization can significantly promote the development of OFDI, that is, the rational development of industrial structure builds a higher platform to offer enterprises a better and further "going out". To this, we can fully tap the important economic and institutional factors behind promoting industrial structure rationalization, such as to get hold of the logic relationship of different development factors, to promote the further optimization of industrial structure under overall arrangements, and to improve the economic benefits finally.

\section{References}

[1] Vernon, R. (1966) International Investment and International Trade in the Product Cycle. The Quarterly Journal of Economics, 2, 190-207. http://dx.doi.org/10.2307/1880689

[2] Lewis, A. (1978) Evolution of the International Economic Order. Princeton University Press, Princeton.

[3] Kojima, K. (1978) Direct Foreign Investment: A Japanese Model of Multinational on Business Operations. Groon Helm, London.

[4] Ozawa, T. (1992) Foreign Direct Investment and Economic Development. Transnational Corporations, 1, 27-54.

[5] Dunning, J.H. (1993) Multinational Enterprises and Global Economy. Addison-Wesley, Wokingham.

[6] Dowling, M. and Cheang, C.T. (2000) Shifting Comparative Advantage in Asia: New Tests of "Flying Geese" the Model. Journal of Asian Economics, 4, 443-463. http://dx.doi.org/10.1016/S1049-0078(00)00070-1

[7] Robert, E.L. (2002) Home and Host Country Effects of FDI. NBER Working Paper.

[8] Wang, Q. (2004) Industrial Structure Adjustment Effect of Outward FDI to the Investor and Its Transmission Mechanism. Journal of International Trade, 5, 73-77.

[9] Fang, H.H. and Wang, X.N. (2006) Impact of Outward FDI on the Domestic Industrial Structure. Science and Technology Management Research, 11, 56-58, 62.

[10] Feng, C.X. (2009) An Empirical Study on China's Outward FDI and Industrial Structure’s Optimization: Taking Manufacturing Industry as an Example. Journal of International Trade, 8, 97-104. 
[11] Zhao, W. and Jiang, D. (2010) ODI and China’s Industrial Upgrading: Mechanism Analysis and Empirical Checking. Journal of Zhejiang University, 1, 1-10.

[12] Zhao, M. and Zhang, R. (2013) The Relations between Jiangsu Province’s Outward FDI and Industrial Structure Adjustment Based on the Framework of VAR Model. Science and Technology Management Research, 4, 95-98, 107.

[13] Jin, T. and Chen, J.J. (2013) Can Inter-Governmental Transfer Payments Improve the Rationalization of Industrial Structure-An Empirical Test Based on Provincial Panel Data from 1994 to 2011. Finance \& Economics, 10, 79-89. 